OPEN ACCESS

Edited by:

Andreas Habenicht,

Ludwig Maximilian University of

Munich, Germany

Reviewed by:

Burkhard Ludewig,

Kantonal Hospital St. Gallen,

Switzerland

Ann Ager,

Cardiff University, UK

*Correspondence:

Walter J. Storkus

storkuswj@upmc.edu

Specialty section:

This article was submitted to

Inflammation,

a section of the journal

Frontiers in Immunology

Received: 05 May 2016

Accepted: 26 July 2016

Published: 09 August 2016

Citation:

Weinstein AM and Storkus WJ (2016)

Biosynthesis and Functional

Significance of Peripheral Node Addressin in Cancer-Associated TLO.

Front. Immunol. 7:301.

doi: 10.3389/fimmu.2016.00301

\section{Biosynthesis and Functional Significance of Peripheral Node Addressin in Cancer-Associated TLO}

\author{
Aliyah M. Weinstein ${ }^{1}$ and Walter J. Storkus ${ }^{1,2,3 *}$ \\ ${ }^{1}$ Department of Immunology, University of Pittsburgh School of Medicine, Pittsburgh, PA, USA, ${ }^{2}$ Department of \\ Dermatology, University of Pittsburgh School of Medicine, Pittsburgh, PA, USA, ${ }^{3}$ University of Pittsburgh Cancer Institute, \\ Pittsburgh, PA, USA
}

Peripheral node addressin (PNAd) marks high endothelial venules (HEV), which are crucial for the recruitment of lymphocytes into lymphoid organs in non-mucosal tissue sites. PNAd is a sulfated and fucosylated glycoprotein recognized by the prototypic monoclonal antibody, MECA-79. PNAd is the ligand for L-selectin, which is expressed on the surface of naive and central memory $T$ cells, where it mediates leukocyte rolling on vascular endothelial surfaces. Although PNAd was first identified in the HEV of peripheral lymph nodes, recent work suggests a critical role for PNAd in the context of chronic inflammatory diseases, where it can be used as a marker for the formation of tertiary lymphoid organs (TLOs). TLO form in tissues impacted by sustained inflammation, such as the tumor microenvironment where they function as local sites of adaptive immune cell priming. This allows for specific B- and T-cell responses to be initiated or reactivated in inflamed tissues without dependency on secondary lymphoid organs. Recent studies of cancer in mice and humans have identified PNAd as a biomarker of improved disease prognosis. Blockade of PNAd or its ligand, L-selectin, can abrogate protective antitumor immunity in murine models. This review examines pathways regulating PNAd biosynthesis by the endothelial cells integral to HEV and the formation and maintenance of lymphoid structures throughout the body, particularly in the setting of cancer.

\section{Keywords: high endothelial venule, L-selectin, peripheral node addressin, tertiary lymphoid organ, tumor}

\section{PATHWAYS REGULATING PNAd EXPRESSION}

\section{Signaling Through the Lymphotoxin Beta Receptor Is Required for HEV Differentiation}

Lymphotoxin beta receptor (LTßR) signaling drives expression of adhesion molecules and chemokines involved in the recruitment of circulating lymphocytes into lymphoid organs, including CCL21, CXCL13, MAdCAM-1, and peripheral node addressin (PNAd) (1). Specifically, expression of LT $\beta R$ on endothelial cells in peripheral lymph nodes is required for their development into high

\footnotetext{
Abbreviations: BGC, germinal center B cell; BV, blood vessel; cDC, conventional dendritic cell; fDC, follicular dendritic cell; Gal, galactose; GalNAc, $N$-acetylgalactosamine; GlcNAc, $N$-acetylglucosamine; HEC, high endothelial cell; HEV, high endothelial venule; HVEM, herpes virus entry mediator; PNAd, peripheral node addressin; SA, sialic acid; SLO, secondary lymphoid organ; TLO, tertiary lymphoid structure; TME, tumor microenvironment; TNFR, tumor necrosis factor receptor; VSMC, vascular smooth muscle cell.
} 
endothelial venules (HEV), with high endothelial cells (HEC) functioning as lymphoid tissue organizer (LTo) cells. Endothelial cell-specific deletion of LT $\beta R$ leads to a reduction in: (i) MECA79 staining, (ii) CCL19, CCL21, and GlyCAM-1 expression, and (iii) the ability to assume cuboidal morphology by endothelial cells in peripheral lymphoid organs [Figure 1A; (2)]. In vivo work using bone marrow chimeric mice deficient in LT $\alpha$ in their hematopoietic compartment also implicates a role for LT $\beta$ Rmediated signaling in the maintenance of HEV, as these mice exhibit profoundly reduced lymph node cellularity (3).

LT $\alpha_{1} \beta_{2}$ and LIGHT can bind and signal through the LT $\beta$ R, while a related ligand, $\mathrm{LT} \alpha_{3}$, can signal through TNFRI, TNFRII, and HVEM. All three ligands can be produced by CD11c ${ }^{+} \mathrm{DC}$ (3). However, each ligand appears to have a distinct role in regulating PNAd expression. In secondary lymphoid organs (SLO), LIGHT appears to have little impact on PNAd expression (4). Using a transgenic model of lymphotoxin overexpression in the pancreas, it was observed that LT $\alpha$ and LT $\beta$ play distinct roles in the formation of tertiary lymphoid organs (TLOs). LT $\alpha_{1} \beta_{2}$ controls luminal PNAd expression, while $\mathrm{LT} \alpha_{3}$ controls abluminal PNAd expression (1). These differences in ligand function appear to relate to their impact on the level of GlcNAc6ST expression by endothelial cells. GlcNAc6ST-2 expression was reduced if only LT $\alpha$, but not LT $\beta$, was present, with HEV in LT $\beta^{-/-}$animals (that retained GlcNAc6ST-2) expressing PNAd (1). $\mathrm{LT}^{-/-}$animals were deficient in GlcNAc6ST-2 expression on HEV, although they retained PNAd expression (5). Blockade of LT $\beta$ R signaling also decreases transcription of GlcNAc6ST-2 in lymph nodes by 10-fold, with GlcNAc6ST-1, FucT-VII, and FucT-IV levels also coordinately reduced, thereby limiting posttranslational modification of PNAd and inhibiting its ability to be recognized by L-selectin (4).

Lymphocytes are also able to secrete lymphotoxin ligands $(2,4)$. Interestingly, the requirement for T or B cells themselves in HEV activation in SLO is equivocal. Reports suggest that neither cell type is required for HEV differentiation (4), although it has also been observed that $\mathrm{Rag}^{-/^{-}}$mice exhibit decreased expression of GlcNAc6ST-2 compared to WT mice (6).

\section{Posttranslational Modifications Are Required for L-Selectin Recognition of PNAd}

Members of the PNAd family of addressins include GlyCAM-1, CD34, sgp200, podocalyxin, endomucin, and nepmucin: however, not all PNAd ligands appear to be required for lymphocyte trafficking $(7,8)$. For example, lymphocyte trafficking to peripheral lymph nodes remains unaltered in $\mathrm{CD} 34^{-/-}$(9) or GlyCAM1 ${ }^{-/-}$ (10) mice, suggesting redundancy in the functional roles of PNAd family members. In order for PNAd to be recognized by MECA79 as well as its receptor, L-selectin, a series of posttranslational modifications must first occur (Figure 1). Specifically, while PNAd undergoes sulfation and glycosylation (11), it is sulfation of the 6 sialyl Lewis X motif that renders these molecules recognizable by the MECA-79 antibody (12). Fucosylation of the Core 2 branched $O$-glycan serves as the recognition site of PNAd by L-selectin (Figure 1B) $(13,14)$.

\section{Sulfation}

GlcNAc6ST-1 and GlcNAc6ST-2 are members of the GalNAc6ST6-O-sulfotransferase subfamily of glycosyl sulfotransferases that are critical to the transfer of sulfate groups to galactose or GlcNAc at the sixth position, with this sulfation of carbohydrate motifs on PNAd required for it to be presented at the cell surface and to be recognized by the MECA-79 antibody and by its natural ligand, L-selectin (15).

Though related, GlcNAc6ST-1 and GlcNAc6ST-2 have different roles in the sulfation of PNAd. Using mice deficient in either single sulfotransferase, it was shown that GlcNAc6ST-2 controls luminal expression of PNAd while GlcNAc6ST-1 controls expression of PNAd on the abluminal vascular surface $(16,17)$.

GlcNAc6ST-2 is expressed by mature, but not immature, HEV. Using a Cre-recombinase model, Kawashima and colleagues observed that expression of GlcNAc6ST-2 is activated in HEV cells recognized by the MECA-79 antibody (i.e., expressing PNAd), but not in cells reactive only with the MECA-367 antibody (recognizing MAdCAM-1) (18). This is consistent with observations that GINAc6ST-1 and -2 have little impact on cellular expression of MAdCAM-1, a canonical marker of immature HEV in SLO within non-mucosal tissue sites (19).

\section{Glycosylation}

A family of $\alpha$ - $(1,3)$-fucosyltransferases control the fucosulation of E-, P-, and L-selectin ligands (20). In particular, FucT-VII and FucT-IV play distinct roles in the generation of L-selectin ligands on the surface of HEV. FucT-IV is required for the expression of L-selectin ligands on the surface of HEV, whereas the primary role of FucT-VII appears to be in its contribution to enhancing GlyCAM-1-mediated tethering of rolling lymphocytes. The specific role of FucT-VII temporally follows glycosylation and sulfation of the glycoprotein and is involved in capping the molecule to produce the preferred ligand recognized by L-selectin. Double knockout of both FucT-VII and FucT-IV in mice reduced lymphocyte recruitment to SLO by over $80 \%$ when compared to FucT-VII ${ }^{-/-}$mice (21).

\section{MARKERS OF HIGH ENDOTHELIAL VENULES}

Two sets of adhesion molecules dominantly modulate lymphocyte recruitment to SLO/TLO depending upon which site in the body the cells are trafficking to: recruitment to peripheral lymph nodes is dependent upon the L-selectin-PNAd interaction, while recruitment to mucosal sites requires the $\alpha_{4} \beta_{7}$ integrinMAdCAM-1 interaction (22). The same HEC that express PNAd or MAdCAM-1 also express CCL21, a CCR7 ligand. Supporting the importance of PNAd- and CCL21-expressing HEV for the recruitment of lymphocytes, the majority of lymphocytes in HEV-expressing tissues are spatially located within approximately $20 \mu \mathrm{m}$ of HEV (23). CCL21 preferentially recruits CCR7 ${ }^{+}$ $\mathrm{CD}^{+} \mathrm{L}^{-}$-selectin ${ }^{+}$(naive) $\mathrm{T}$ cells, which can interact with PNAd on the cells of the HEV. CCL21, like PNAd, is under the control of intrinsic LT $\beta$ R-mediated signaling during HEV development (but not in mature lymphoid tissues) $(1,4)$. 
A
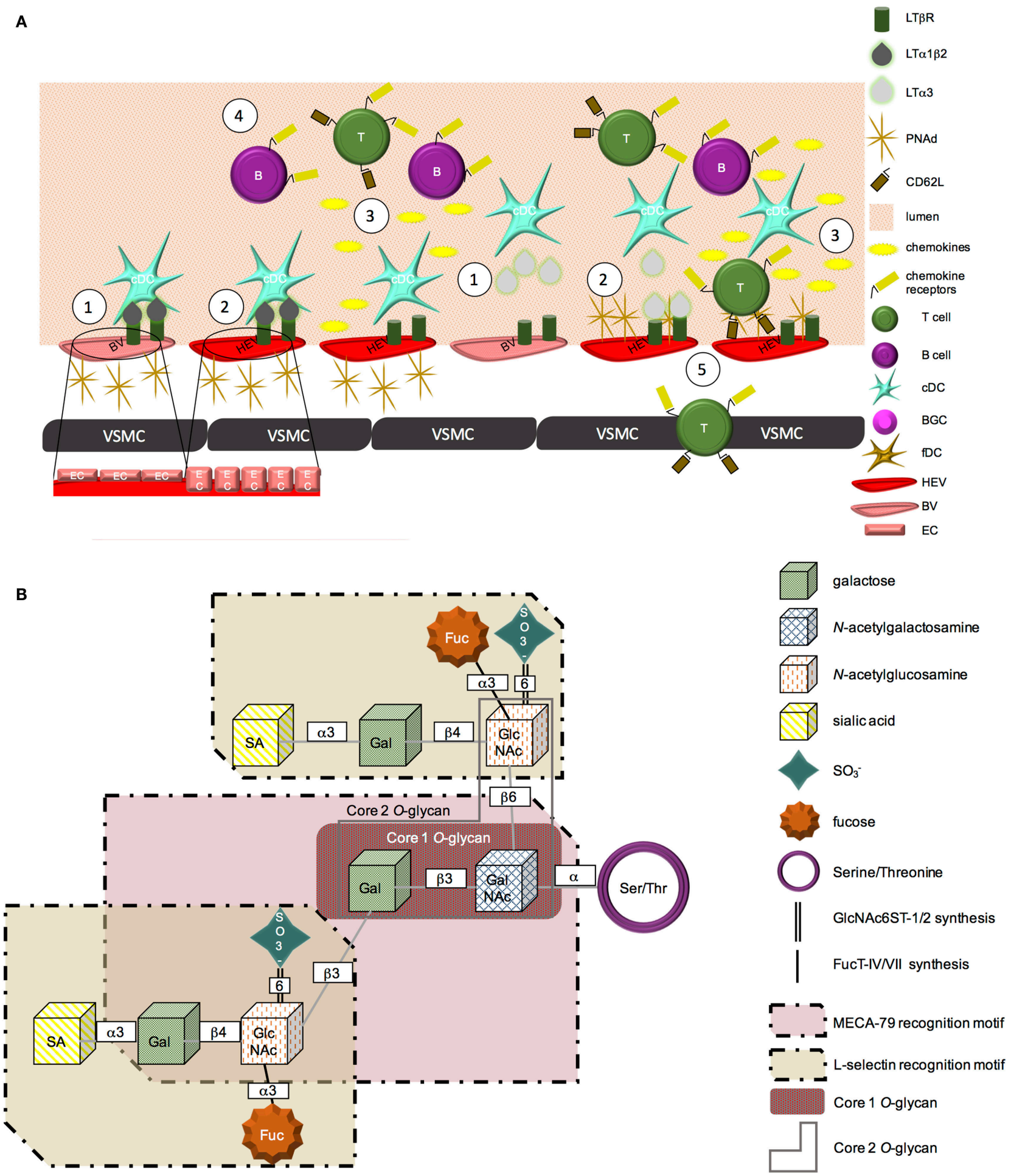

FIGURE 1 | PNAd biosynthesis. (A) (1) LT $\beta R$ is expressed on blood vessel endothelial cells. Membrane-bound LT $\alpha 1 \beta 2$ or secreted $L T \alpha 3$ secreted from cDC can signal through this receptor. (2) LT $\beta R$-mediated signaling promotes a physical change in vascular endothelial cells from a flat to cuboidal morphology. This signaling cascade also leads to the expression of PNAd on the surface of vascular endothelial cells, promoting HEV status. (3) LT $\beta R$ signaling further induces HEV secreted chemokines, including CCL19, CCL21, and CXCL13. (4) Chemokines form gradients and "decorate" the blood vessel wall, initiating the recruitment of CCR7 ${ }^{+} T$ cells or CXCR5+ B lymphocytes from the peripheral blood circulation into chronically inflamed tissues. (5) L-selectin on the surface of T cells is able to bind PNAd on the surface of HEV. These cells are then able to adhere to the vessel wall and extravasate into the tissue. (B) PNAd is synthesized from a Core 1 O-glycan. The extended Core 1 O-glycan serves as the MECA-79 recognition motif. The fucosylated Core 2 O-glycans are able to be recognized by L-selectin. Sulfation of the extended Core 1 and Core 2 O-glycans at the sixth position is mediated by GlcNAc6ST-1 and -2; $\alpha 3$ fucosylation is added by FucT-IV and -VII. 


\section{IMMUNE CELL RECRUITMENT BY HEV}

Peripheral node addressin binds L-selectin (aka CD62L or LECAM-1) expressed on the surface of lymphocytes. This interaction is required for the recruitment of lymphocytes into SLO (24). Posttranslational modifications of PNAd family members are critical for this interaction. For example, B cell recruitment to peripheral lymph nodes is dependent on sulfation of PNAd (19). The velocity of T and B cell rolling is also dependent upon sulfation of L-selectin ligands on lymph node endothelial cells, with adherence of lymphocytes to the vessel wall decreased in GlcNAc6ST-deficient animals (19). This may also be controlled by the presence of DC within SLO, as the velocity of lymphocyte rolling in CD11c-DTR mice was significantly increased, and the percentage of lymphocytes able to adhere to the vessel wall was decreased, in these mice after treatment with diphtheria toxin to delete DC. The HEV of DC-depleted mice regained expression of MAdCAM-1, and after reconstitution with adoptively transferred CD11 ${ }^{+}$DC, these HEV recovered classical cuboidal morphology, suggesting that DC-produced factor(s) is/are required for the maturation of $\mathrm{HEV}$ (3).

The CCR7-CCL21 axis is also important for lymphocyte recruitment into lymphoid organs. Mice deficient in CCR7 have impaired migration of B and T cells, as well as DC, to SLO including lymph nodes and Peyer's patches. This limits primary immune responses against infectious agents (25). Expression of CCL 21 by HEC is controlled by a pathway unique to these cells versus HEC expressing alternate addressins. Specifically, heparan sulfate, a glycosaminoglycan primarily found on the surface of vascular endothelial cells, is required for CCL21 expression on HEV (26). Using an Ext1-flox/flox mouse crossed with a GlcNAc6ST-2-cre transgenic mouse to delete a glycosyltransferase necessary for the synthesis of heparan sulfate in PNAd-expressing cells, expression of CCL21 on the surface of HEV was abrogated (23).

\section{TERTIARY LYMPHOID ORGANS}

Although the pioneering work identifying PNAd and the pathways controlling its expression were initially studied in the context of SLO, recent literature supports an important role for PNAd in TLO (aka ectopic lymphoid structures) that develop in peripheral tissue sites impacted by chronic inflammation. Overall, TLOs have varying degrees of similarity to SLO. Classical TLO closely resembles SLO in their cellular composition, with TLO containing a network of follicular dendritic cells (fDC) and germinal centers in which $\mathrm{B}$ cells reside, proliferate, and differentiate (Figure 2A). Non-classical TLO also contain some degree of B cell infiltration, but they do not exhibit an fDC "framework" (27), with only diffuse, sparse B cell distributions being observed (Figure 2B) (28-30).

The L-selectin-PNAd interaction controls lymphocyte recruitment to TLOs. In particular, PNAd upregulation in affected tissues is observed in the settings of allergic contact dermatitis, lymphoid hyperplasia, and a variety of types of skin lesions and cutaneous lymphomas, i.e., diseases characterized by robust lymphocytic infiltrates into peripheral tissues (31). The CCR7 signaling axis also plays a role in TLO formation. Most importantly, CCR7-mediated signals are required for the clustering of $\mathrm{DC}$ in peripheral tissues. Interactions between DC and T cells proximal to blood vessels appears required for the acquisition of PNAd + HEV in peripheral tissues (5).

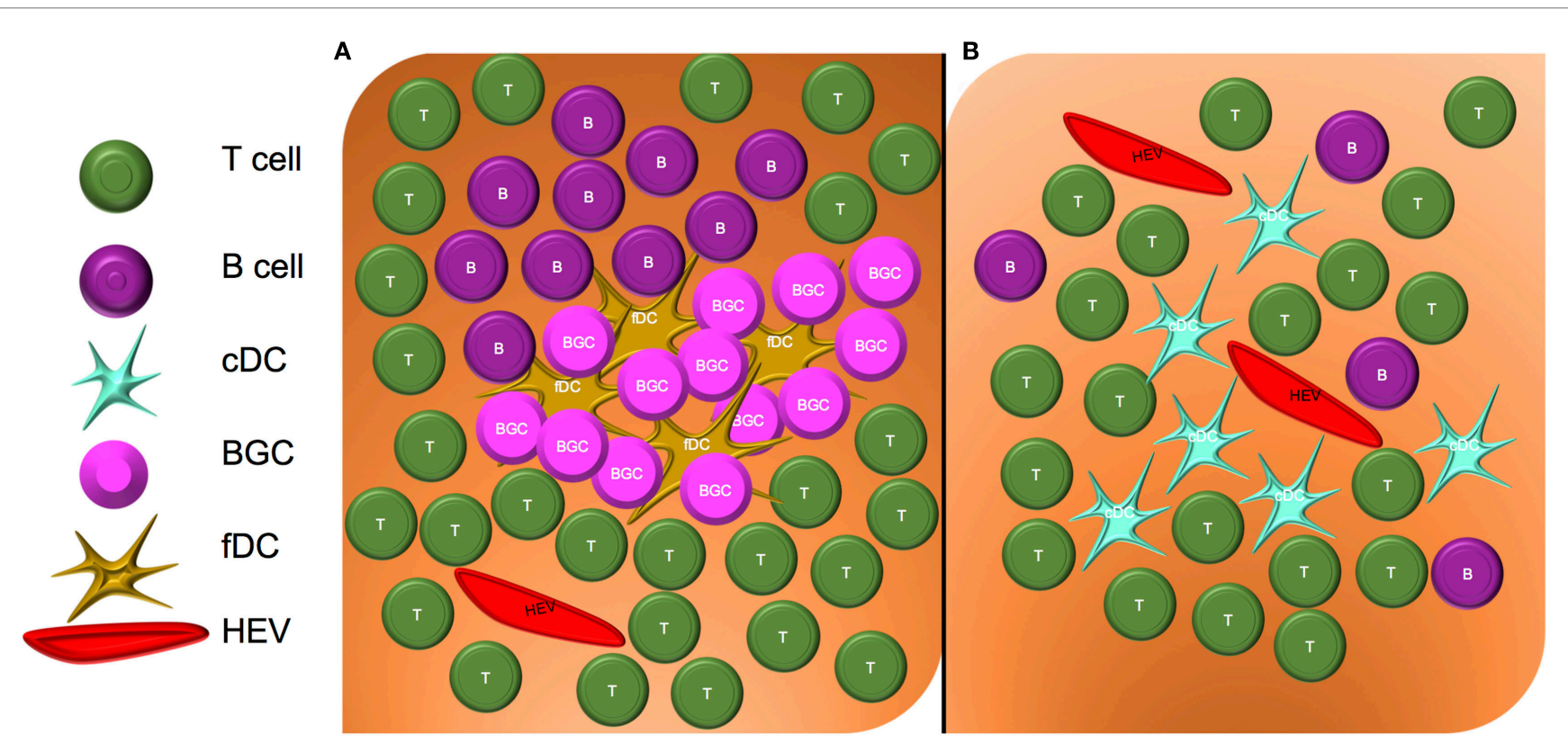

FIGURE 2 | Structure of classical and non-classical tertiary lymphoid organs. (A) Classical TLO contain a nucleated core of fDC and germinal center B cells (BGC), surrounded by an HEV-containing T cell zone. (B) Non-classical TLO do not contain fDC or BGC, but may contain sparse B cell, T cell, and DC infiltrates surrounding HEV. 
Notably, LT $\beta$ R-mediated signaling controls the formation of HEV in peripheral tissues $(5,32)$. Akin to the roles that lymphotoxin signaling plays in the control of PNAd expression in SLO, LT $\alpha 3$-dependent signaling has been reported to dominantly control PNAd expression on HEV within the tumor microenvironment (TME) in murine melanoma models (32), while in human breast cancer, LT $\beta$ (produced by DC-LAMP + DC) appears to play a comparable dominant role (33).

Tertiary lymphoid organs have been observed in a variety of chronic inflammatory diseases, including arthritis (34), gastritis and ulcerative colitis $(13,35)$, atherosclerosis (36), and cancer (37). As the development of TLO in chronic/autoimmune diseases has been well-reviewed $(38,39)$, we will now focus on the emerging field of TLO formation in solid tumors.

\section{TLO in Cancer}

Cancer-associated TLO characteristically contain PNAd $^{+}$vessels and are commonly localized to the outer margin (versus the core) of the tumor lesion (40). With the exception of reports for TLO predicting a worse prognosis in patients with renal cell carcinoma (RCC) (41) and some cases of colorectal cancer (42), the vast weight of the literature has correlated the presence of TLOs in human solid tumors with better clinical prognoses (43). Both classical and non-classical TLO have been reported within the TME (Figure 2). Of these two forms of TLO, however, the presence of classical TLO in tumors may provide a superior index for improved prognosis when compared to the presence of only non-classical TLO in the TME (27). These results suggest that systematic analysis of PNAd expression and TLO status in tumor biopsies may be a useful in addition to current clinical criteria used to predict patient outcomes.

\section{Lung Cancer}

In non-small-cell lung cancer (NSCLC), NAd $^{+}$vessels have been identified exclusively within TLO (44). In these tumors, the composition of cells within the TLO specifically correlates with patient prognosis. While $\mathrm{T}$ cells (all tumor-infiltrating L-selectin ${ }^{+} \mathrm{T}$ cells, comprised of both naive and central memory $\mathrm{CD}^{+}$and $\mathrm{CD}^{+}$cells) are localized to $\operatorname{TLO}(44,45)$, overall $T$ cell infiltrate and density appears to play a minor role in patient outcome when evaluated independently of other prognostic markers. Instead, the density and proximity of mature DC to TLO within the tumor may be most important, and patients with

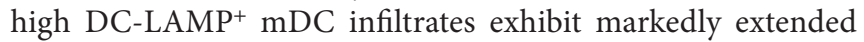
overall survival (45). These findings are further supported by gene array data indicating that CXCR4, a gene associated with DC migration toward CXCL12 gradients, is strongly correlated with increased overall survival in NSCLC patients (46). Unlike $\mathrm{T}$ cells, B cells do appear to play a significant protective role against lung cancer, and their presence can be used as a positive prognostic marker of overall survival. Interestingly, DC and $\mathrm{B}$ cell density in TLO can be used as a coordinate prognostic marker for patients with greatest overall survival. In NSCLC, B cells organize into germinal center-like structures containing $\mathrm{CD} 21^{+} \mathrm{fDC}$. These B cells proliferate and differentiate in situ, leading to locoregional secretion of $\operatorname{IgG}$ and $\operatorname{IgA}$ antibodies reactive against tumor-associated antigens (47).

\section{Skin Cancers}

Tertiary lymphoid organs have been identified in both primary and metastatic melanoma, where they have been observed to contain PNAd $^{+}$vessels $(48,49)$. TLO in primary melanomas can be either classical or non-classical TLO. In metastatic melanoma, these structures are primarily composed of $\mathrm{CD}^{+}$ $\mathrm{T}$ cells and mature (DC-LAMP ${ }^{+}$) DC proximal to $\mathrm{PNAd}^{+} \mathrm{HEV}$ (50). Plasma B cells may also be present in such TLO, with these cells producing Th-dependent IgG and IgA antibodies specific for tumor-associated antigens $(48,50)$. In primary cutaneous melanoma, the presence of intratumoral HEV has been correlated with robust lymphocytic infiltration and tumor regression. Furthermore, if the HEC making up HEV have a cuboidal morphology, indicative of functional HEV, a positive correlation with CCR7, CCL19, and CCL21 expression within the tumor has also been observed (51).

The presence of TLO also portends better clinical outcome (recurrence free and overall survival) in the setting of Merkel cell carcinoma. These structures are also characterized by an increased $\mathrm{CD} 8^{+} / \mathrm{CD} 4^{+} \mathrm{T}$ cell ratio at the tumor periphery and by a co-clustering of $\mathrm{T}$ and $\mathrm{B}$ cells within these anatomic sites (52).

\section{Colon Cancer}

Tertiary lymphoid organs in human colon cancer have been detected in both the colon crypt and at the invasive front of the tumor, as well as in the peritumoral region $(53,54)$. They contain immune cell types typically observed in SLO, including $\mathrm{B}$ cells, CD $21^{+} \mathrm{fDC}$, T cells, and mature DC marked by DC-LAMP ${ }^{+}$, with $\mathrm{CD}_{31}{ }^{+}$vascular endothelial cells and LYVE$1^{+}$lymphatic vessels also noted $(53,54)$. T cells and mature DC represent positive prognostic markers in both primary (43) and metastatic (41) colorectal cancer. In such tumors, the B cells may not organize into germinal center-like structures $(53,54)$. These TLO appear to function as local sites for the priming and expansion of both $\mathrm{B}$ and $\mathrm{T}$ cells, based on the expression of the Ki-67 marker in de facto germinal centers in these diseased tissues (54).

\section{Therapeutic Induction of TLO}

Recent work from our group suggests that intratumoral TLO can be induced therapeutically via adoptive transfer of genemodified DC, leading to reduced tumor progression. Following intratumoral injection of Type 1-polarized DC (DC engineered to overexpress Tbet, i.e., DC.Tbet) into established murine sarcomas or colon carcinomas, $\mathrm{CD} 4^{+}$and $\mathrm{CD} 8^{+} \mathrm{T}$ cell recruitment to the TME is observed within 2 days, with an upregulation of PNAd expression detected by 5 days after treatment. This suggests that PNAd-independent events control early $\mathrm{T}$ cell recruitment to the TME, and that T cell-dependent factors may consequently result in PNAd upregulation on tumor-associated VEC $(28,29)$. Once established, $\mathrm{PNAd}^{+}$vessels become surrounded by dense infiltrates of both $\mathrm{CD} 11 \mathrm{c}^{+} \mathrm{DC}$ and $\mathrm{CD}^{+} \mathrm{T}$ cells, with these nonclassical TLO principally localized near the tumor periphery for 
at least 2 weeks following initial therapeutic intervention $(28,29)$. The presence of DC in TLO is consistent with prior studies of SLO demonstrating that DC accumulation proximal to $\mathrm{HEV}$ is required for the subsequent optimal homing of lymphocytes into SLO (3).

\section{FUTURE PERSPECTIVES}

Although there appears to be some variability in the cellular composition across tumor types, TLO in the TME contain PNAd ${ }^{+}$ HEV typically surrounded by dense B cell and/or DC infiltrates. Importantly, the presence of intratumoral or peritumoral TLO has been almost universally linked with superior clinical prognosis in patients with solid forms of cancer. Though $\mathrm{T}$ cells are also present in intratumoral TLO, their presence has thus far proven equivocal as a prognostic biomarker. The spontaneous formation of TLO has been observed in a variety of human cancers, including those reviewed above as well as oral squamous cell carcinoma $(27,55)$, gastric cancer $(40,56)$, bladder cancer $(57)$, breast cancer $(30,58,59)$, and others $(37,60)$. Thus, it may ultimately be best to employ PNAd as well as B cell and DC infiltration in the TME

\section{REFERENCES}

1. Drayton DL, Ying X, Lee J, Lesslauer W, Ruddle NH. Ectopic LT alpha beta directs lymphoid organ neogenesis with concomitant expression of peripheral node addressin and a HEV-restricted sulfotransferase. J Exp Med (2003) 197(9):1153-63. doi:10.1084/jem.20021761

2. Onder L, Danuser R, Scandella E, Firner S, Chai Q, Hehlgans T, et al. Endothelial cell-specific lymphotoxin- $\beta$ receptor signaling is critical for lymph node and high endothelial venule formation. J Exp Med (2013) 210(3):465-73. doi:10.1084/jem.20121462

3. Moussion C, Girard J-P. Dendritic cells control lymphocyte entry to lymph nodes through high endothelial venules. Nature (2011) 479(7374):542-6. doi:10.1038/nature 10540

4. Browning JL, Allaire N, Ngam-Ek A, Notidis E, Hunt J, Perrin S, et al. Lymphotoxin-beta receptor signaling is required for the homeostatic control of HEV differentiation and function. Immunity (2005) 23(5):539-50. doi:10.1016/j.immuni.2005.10.002

5. Marinkovic T, Garin A, Yokota Y, Fu Y-X, Ruddle NH, Furtado GC, et al. Interaction of mature $\mathrm{CD} 3+\mathrm{CD} 4+\mathrm{T}$ cells with dendritic cells triggers the development of tertiary lymphoid structures in the thyroid. JClin Invest (2006) 116(10):2622-32. doi:10.1172/JCI28993

6. Liao S, Ruddle NH. Synchrony of high endothelial venules and lymphatic vessels revealed by immunization. J Immunol (2006) 177(5):3369-79. doi:10.4049/jimmunol.177.5.3369

7. Sperandio M, Gleissner CA, Ley K. Glycosylation in immune cell trafficking. Immunol Rev (2009) 230(1):97-113. doi:10.1111/j.1600-065X.2009.00795.X

8. Umemoto E, Tanaka T, Kanda H, Jin S, Tohya K, Otani K, et al. Nepmucin, a novel HEV sialomucin, mediates L-selectin-dependent lymphocyte rolling and promotes lymphocyte adhesion under flow. J Exp Med (2006) 203(6):1603-14. doi:10.1084/jem.20052543

9. Suzuki A, Andrew DP, Gonzalo JA, Fukumoto M, Spellberg J, Hashiyama M, et al. CD34-deficient mice have reduced eosinophil accumulation after allergen exposure and show a novel crossreactive $90-\mathrm{kD}$ protein. Blood (1996) 87(9):3550-62.

10. Rosen SD. Ligands for L-selectin: homing, inflammation, and beyond. Annu Rev Immunol (2004) 22:129-56. doi:10.1146/annurev.immunol.21.090501.080131

11. Arata-Kawai H, Singer MS, Bistrup A, Zante AV, Wang YQ, Ito Y, et al. Functional contributions of $\mathrm{N}$ - and O-glycans to $\mathrm{L}$-selectin ligands in as biomarkers to stratify patients based on TLO status, i.e., to differentiate individuals that may respond better to treatment intervention, including immunotherapies (based on superior locoregional immune competency). Furthermore, because TLO may be induced therapeutically (at least in murine models), it is also intriguing to speculate on the possibility that protective TLO may be conditionally sponsored in patients receiving chemo- or immunotherapies (61), and that such structures may be used to monitor/predict the patient's outcome and prospective treatment management.

\section{AUTHOR CONTRIBUTIONS}

Both authors contributed to the design, writing, and editing of the submitted manuscript.

\section{ACKNOWLEDGMENTS}

The authors wish to thank Ms. Subhara Raveendran for her thoughtful review of this manuscript. This work was supported by NIH R01 CA204419 (to WJS) and NIH T32 AI089443 (to AMW).

murine and human lymphoid organs. Am J Pathol (2011) 178(1):423-33. doi:10.1016/j.ajpath.2010.11.009

12. Hemmerich S, Butcher EC, Rosen SD. Sulfation-dependent recognition of high endothelial venules (HEV)-ligands by L-selectin and MECA 79, and adhesion-blocking monoclonal antibody. J Exp Med (1994) 180(6):2219-26. doi:10.1084/jem.180.6.2219

13. Kobayashi M, Fukuda M, Nakayama J. Role of sulfated O-glycans expressed by high endothelial venule-like vessels in pathogenesis of chronic inflammatory gastrointestinal diseases. Biol Pharm Bull (2009) 32(5):774-9. doi:10.1248/ bpb.32.774

14. Lowe JB. Glycosylation, immunity, and autoimmunity. Cell (2001) 104(6):809-12. doi:10.1016/S0092-8674(01)00277-X

15. Grunwell JR, Bertozzi CR. Carbohydrate sulfotransferases of the GalNAc/ Gal/GlcNAc6ST family. Biochemistry (2002) 41(44):13117-26. doi:10.1021/ bi020507h

16. Hemmerich S, Bistrup A, Singer MS, van Zante A, Lee JK, Tsay D, et al. Sulfation of L-selectin ligands by an HEV-restricted sulfotransferase regulates lymphocyte homing to lymph nodes. Immunity (2001) 15(2):237-47. doi:10.1016/S1074-7613(01)00188-1

17. Uchimura K, Kadomatsu K, El-Fasakhany FM, Singer MS, Izawa M, Kannagi R, et al. $\mathrm{N}$-acetylglucosamine 6-O-sulfotransferase-1 regulates expression of L-selectin ligands and lymphocyte homing. J Biol Chem (2004) 279(33):35001-8. doi:10.1074/jbc.M404456200

18. Kawashima H, Hirakawa J, Tobisawa Y, Fukuda M, Saga Y. Conditional gene targeting in mouse high endothelial venules. J Immunol (2009) 182(9):5461-8. doi:10.4049/jimmunol.0802327

19. Uchimura K, Gauguet J-M, Singer MS, Tsay D, Kannagi R, Muramatsu T, et al. A major class of L-selectin ligands is eliminated in mice deficient in two sulfotransferases expressed in high endothelial venules. Nat Immunol (2005) 6(11):1105-13. doi:10.1038/ni1258

20. Malý P, Thall AD, Petryniak B, Rogers CE, Smith PL, Marks RM, et al. The $\alpha(1,3)$ Fucosyltransferase Fuc-TVII controls leukocyte trafficking through an essential role in L-, E-, and P-selectin ligand biosynthesis. Cell (1996) 86(4):643-53. doi:10.1016/S0092-8674(00)80137-3

21. Homeister JW, Thall AD, Petryniak B, Malý P, Rogers CE, Smith PL, et al. The $\alpha(1,3)$ fucosyltransferases FucT-IV and FucT-VII exert collaborative control over selectin-dependent leukocyte recruitment and lymphocyte homing. Immunity (2001) 15(1):115-26. doi:10.1016/S1074-7613(01)00166-2 
22. Miyasaka M, Tanaka T. Lymphocyte trafficking across high endothelial venules: dogmas and enigmas. Nat Rev Immunol (2004) 4(5):360-70. doi: $10.1038 /$ nril354

23. Tsuboi K, Hirakawa J, Seki E, Imai Y, Yamaguchi Y, Fukuda M, et al. Role of high endothelial venule-expressed heparan sulfate in chemokine presentation and lymphocyte homing. J Immunol (2013) 191(1):448-55. doi:10.4049/ jimmunol.1203061

24. Berg EL, Robinson MK, Warnock RA, Butcher EC. The human peripheral lymph node vascular addressin is a ligand for LECAM-1, the peripheral lymph node homing receptor. J Cell Biol (1991) 114(2):343-9. doi:10.1083/jcb.114.2.343

25. Förster R, Schubel A, Breitfeld D, Kremmer E, Renner-Müller I, Wolf E, et al. CCR7 coordinates the primary immune response by establishing functional microenvironments in secondary lymphoid organs. Cell (1999) 99(1):23-33. doi:10.1016/S0092-8674(00)80059-8

26. Nelson RM, Cecconi O, Roberts WG, Aruffo A, Linhardt RJ, Bevilacqua MP. Heparin oligosaccharides bind L- and P-selectin and inhibit acute inflammation. Blood (1993) 82(11):3253-8.

27. Wirsing AM, Rikardsen OG, Steigen SE, Uhlin-Hansen L, Hadler-Olsen E. Characterisation and prognostic value of tertiary lymphoid structures in oral squamous cell carcinoma. BMC Clin Pathol (2014) 14:38. doi:10.1186/1472-6890-14-38

28. Chen L, Fabian KL, Taylor JL, Storkus WJ. Therapeutic use of dendritic cells to promote the extranodal priming of anti-tumor immunity. Front Immunol (2013) 4:388. doi:10.3389/fimmu.2013.00388

29. Chen L, Taylor JL, Sabins NC, Lowe DB, Qu Y, You Z, et al. Extranodal induction of therapeutic immunity in the tumor microenvironment after intratumoral delivery of Tbet gene-modified dendritic cells. Cancer Gene Ther (2013) 20(8):469-77. doi:10.1038/cgt.2013.42

30. Mahmoud SMA, Lee AHS, Paish EC, Macmillan RD, Ellis IO, Green AR. The prognostic significance of $\mathrm{B}$ lymphocytes in invasive carcinoma of the breast. Breast Cancer Res Treat (2012) 132(2):545-53. doi:10.1007/s10549-0111620-1

31. Michie SA, Streeter PR, Bolt PA, Butcher EC, Picker LJ. The human peripheral lymph node vascular addressin. An inducible endothelial antigen involved in lymphocyte homing. Am J Pathol (1993) 143(6):1688-98.

32. Peske JD, Thompson ED, Gemta L, Baylis RA, Fu Y-X, Engelhard VH. Effector lymphocyte-induced lymph node-like vasculature enables naive T-cell entry into tumours and enhanced anti-tumour immunity. Nat Commun (2015) 6:7114. doi:10.1038/ncomms8114

33. Martinet L, Filleron T, Le Guellec S, Rochaix P, Garrido I, Girard J-P. High endothelial venule blood vessels for tumor-infiltrating lymphocytes are associated with lymphotoxin-producing dendritic cells in human breast cancer. J Immunol (2013) 191(4):2001-8. doi:10.4049/jimmunol.1300872

34. Yang J, Rosen SD, Bendele P, Hemmerich S. Induction of PNAd and $\mathrm{N}$-acetylglucosamine 6-O-sulfotransferases 1 and 2 in mouse collagen-induced arthritis. BMC Immunol (2006) 7:12. doi:10.1186/1471-2172-7-12

35. Kobayashi M, Hoshino H, Masumoto J, Fukushima M, Suzawa K, Kageyama S, et al. GlcNAc6ST-1-mediated decoration of MAdCAM-1 protein with L-selectin ligand carbohydrates directs disease activity of ulcerative colitis. Inflamm Bowel Dis (2009) 15(5):697-706. doi:10.1002/ibd.20827

36. Hu D, Mohanta SK, Yin C, Peng L, Ma Z, Srikakulapu P, et al. Artery tertiary lymphoid organs control aorta immunity and protect against atherosclerosis via vascular smooth muscle cell lymphotoxin $\beta$ receptors. Immunity (2015) 42(6):1100-15. doi:10.1016/j.immuni.2015.05.015

37. Pimenta EM, Barnes BJ. Role of tertiary lymphoid structures (TLS) in anti-tumor immunity: potential tumor-induced cytokines/chemokines that regulate TLS formation in epithelial-derived cancers. Cancers (Basel) (2014) 6(2):969-97. doi:10.3390/cancers6020969

38. Neyt K, Perros F, GeurtsvanKessel CH, Hammad H, Lambrecht BN. Tertiary lymphoid organs in infection and autoimmunity. Trends Immunol (2012) 33(6):297-305. doi:10.1016/j.it.2012.04.006

39. Pitzalis C, Jones GW, Bombardieri M, Jones SA. Ectopic lymphoid-like structures in infection, cancer and autoimmunity. Nat Rev Immunol (2014) 14(7):447-62. doi:10.1038/nri3700

40. Enarsson K, Johnsson E, Lindholm C, Lundgren A, Pan-Hammarström Q, Strömberg E, et al. Differential mechanisms for T lymphocyte recruitment in normal and neoplastic human gastric mucosa. Clin Immunol (2006) 118(1):24-34. doi:10.1016/j.clim.2005.08.001
41. Remark R, Alifano M, Cremer I, Lupo A, Dieu-Nosjean M-C, Riquet M, et al. Characteristics and clinical impacts of the immune environments in colorectal and renal cell carcinoma lung metastases: influence of tumor origin. Clin Cancer Res (2013) 19(15):4079-91. doi:10.1158/1078-0432.CCR-12-3847

42. Bento DC, Jones E, Junaid S, Tull J, Williams GT, Godkin A, et al. High endothelial venules are rare in colorectal cancers but accumulate in extra-tumoral areas with disease progression. Oncoimmunology (2015) 4(3):e974374. doi:10 $.4161 / 2162402 X .2014 .974374$

43. Fridman WH, Pagès F, Sautès-Fridman C, Galon J. The immune contexture in human tumours: impact on clinical outcome. Nat Rev Cancer (2012) 12(4):298-306. doi:10.1038/nrc3245

44. de Chaisemartin L, Goc J, Damotte D, Validire P, Magdeleinat P, Alifano M, et al. Characterization of chemokines and adhesion molecules associated with $\mathrm{T}$ cell presence in tertiary lymphoid structures in human lung cancer. Cancer Res (2011) 71(20):6391-9. doi:10.1158/0008-5472.CAN-11-0952

45. Goc J, Germain C, Vo-Bourgais TKD, Lupo A, Klein C, Knockaert S, et al. Dendritic cells in tumor-associated tertiary lymphoid structures signal a Th1 cytotoxic immune contexture and license the positive prognostic value of infiltrating CD8+ T cells. Cancer Res (2014) 74(3):705-15. doi:10.1158/00085472.CAN-13-1342

46. Kossenkov AV, Dawany N, Evans TL, Kucharczuk JC, Albelda SM, Showe LC, et al. Peripheral immune cell gene expression predicts survival of patients with non-small cell lung cancer. PLoS One (2012) 7(3):e34392. doi:10.1371/journal. pone. 0034392

47. Germain C, Gnjatic S, Tamzalit F, Knockaert S, Remark R, Goc J, et al. Presence of $\mathrm{B}$ cells in tertiary lymphoid structures is associated with a protective immunity in patients with lung cancer. Am J Respir Crit Care Med (2014) 189(7):832-44. doi:10.1164/rccm.201309-1611OC

48. Cipponi A, Mercier M, Seremet T, Baurain J-F, Théate I, van den Oord J, et al. Neogenesis of lymphoid structures and antibody responses occur in human melanoma metastases. Cancer Res (2012) 72(16):3997-4007. doi:10.1158/0008-5472.CAN-12-1377

49. Martinet L, Garrido I, Filleron T, Le Guellec S, Bellard E, Fournie J-J, et al. Human solid tumors contain high endothelial venules: association with T- and B-lymphocyte infiltration and favorable prognosis in breast cancer. Cancer Res (2011) 71(17):5678-87. doi:10.1158/0008-5472.CAN-11-0431

50. van Baren N, Baurain J-F, Coulie PG. Lymphoid neogenesis in melanoma: what does it tell us? Oncoimmunology (2013) 2(1):e22505. doi:10.4161/onci.22505

51. Avram G, Sánchez-Sendra B, Martín JM, Terrádez L, Ramos D, Monteagudo C. The density and type of MECA-79-positive high endothelial venules correlate with lymphocytic infiltration and tumour regression in primary cutaneous melanoma. Histopathology (2013) 63(6):852-61. doi:10.1111/his.12235

52. Behr DS, Peitsch WK, Hametner C, Lasitschka F, Houben R, Schönhaar K, et al. Prognostic value of immune cell infiltration, tertiary lymphoid structures and PD-L1 expression in Merkel cell carcinomas. Int J Clin Exp Pathol (2014) 7(11):7610-21.

53. Bergomas F, Grizzi F, Doni A, Pesce S, Laghi L, Allavena P, et al. Tertiary intratumor lymphoid tissue in colo-rectal cancer. Cancers (Basel) (2011) 4(1):1-10. doi:10.3390/cancers4010001

54. Coppola D, Nebozhyn M, Khalil F, Dai H, Yeatman T, Loboda A, et al. Unique ectopic lymph node-like structures present in human primary colorectal carcinoma are identified by immune gene array profiling. Am J Pathol (2011) 179(1):37-45. doi:10.1016/j.ajpath.2011.03.007

55. Shen H, Wang X, Shao Z, Liu K, Xia X-Y, Zhang H-Z, et al. Alterations of high endothelial venules in primary and metastatic tumors are correlated with lymph node metastasis of oral and pharyngeal carcinoma. Cancer Biol Ther (2014) 15(3):342-9. doi:10.4161/cbt.27328

56. Kobayashi M, Mitoma J, Hoshino H, Yu S-Y, Shimojo Y, Suzawa K, et al. Prominent expression of sialyl Lewis X-capped core 2-branched O-glycans on high endothelial venule-like vessels in gastric MALT lymphoma. J Pathol (2011) 224(1):67-77. doi:10.1002/path.2851

57. Taga M, Hoshino H, Low S, Imamura Y, Ito H, Yokoyama O, et al. A potential role for 6-sulfo sialyl Lewis $\mathrm{X}$ in metastasis of bladder urothelial carcinoma. Urol Oncol (2015) 33(11):.e1-9. doi:10.1016/j.urolonc.2015.05.026

58. Denkert C, Loibl S, Noske A, Roller M, Müller BM, Komor M, et al. Tumor-associated lymphocytes as an independent predictor of response to neoadjuvant chemotherapy in breast cancer. J Clin Oncol (2010) 28(1):105-13. doi:10.1200/JCO.2009.23.7370 
59. Nzula S, Going JJ, Stott DI. Antigen-driven clonal proliferation, somatic hypermutation, and selection of B lymphocytes infiltrating human ductal breast carcinomas. Cancer Res (2003) 63(12):3275-80. doi:10.4049/ jimmunol.169.5.2701

60. Weinstein AM, Storkus WJ. Therapeutic lymphoid organogenesis in the tumor microenvironment. Adv Cancer Res (2015) 128:197-233. doi:10.1016/ bs.acr.2015.04.003

61. Stoll G, Enot D, Mlecnik B, Galon J, Zitvogel L, Kroemer G. Immunerelated gene signatures predict the outcome of neoadjuvant chemotherapy. Oncoimmunology (2014) 3(1):e27884. doi:10.4161/onci.27884
Conflict of Interest Statement: The authors declare that the research was conducted in the absence of any commercial or financial relationships that could be construed as a potential conflict of interest.

Copyright (C) 2016 Weinstein and Storkus. This is an open-access article distributed under the terms of the Creative Commons Attribution License (CC BY). The use, distribution or reproduction in other forums is permitted, provided the original author(s) or licensor are credited and that the original publication in this journal is cited, in accordance with accepted academic practice. No use, distribution or reproduction is permitted which does not comply with these terms. 